\title{
Studies of Solvent Effect of Aquo-Methanol Solvent System on Kinetics and Activation Parameters of Base Catalised Hydrolysis of Ethyl Cinnamate
}

\author{
A.K. Singh \\ Department of Chemistry \\ Teerthanker Mahaveer University, Moradabad, India
}

\begin{abstract}
The rate of alkaline hydrolysis of ethyl cinamate was measured over the temperature range of $20^{\circ} \mathrm{C}$ to $40^{\circ} \mathrm{C}$ in watermethanol mixture at different composition 30 to $70 \%$ (v/v).The specific rate constant was calculated using second order reaction. The influence of solvent variation on reaction rate was examined in term of changes in the Activation parameter. Depletion of $\Delta \mathbf{H}^{*}$ and $\Delta \mathbf{S}^{*}$ value with simultaneous increase in $\Delta \mathbf{G}^{*}$ of the reaction in media, reveals that the reaction is Enthalpy domination and Entropy controlled. The Values of Iso-kinetic which is less than 300, clearly indicates that there is no appreciable interaction between solvent and solute present in the reaction media, i.e. reaction is not ion-dipole but ion-molecule type.
\end{abstract}

Keywords- Activation Parameter, Solvent effect, solvent-solute interaction, Iso-kinetic temperature, specific salvation

\section{INTRODUCTION}

Though the solvent effect on the rate and mechanism of the various type of reaction has been reported [1] [2] [3] but very little attention has been paid towards the study of the solvent effect on the thermodynamic activation parameter and solventsolute interaction, particularly solvolysis of Ethyl Cinamate which is important for medicinal use as well as flavoring agent in cut tobacco. It has been proposed to make a kinetic study of the solvent effect on the base catalyzed hydrolysis Ethyl Cennamate in water-methanol media of various compositions.

\section{EXPERIMENTAL}

The kinetics of base catalyzed hydrolysis of ethyl acetate has been carried out volumetric in water-methanol and waterethanol having different concentration of solvent (methanol) varying from 30 to $70 \%(\mathrm{v} / \mathrm{v})$ at five different temperatures ranging from $20^{\circ} \mathrm{C}$ to $40^{\circ} \mathrm{C}$ at regular interval of $5^{\circ} \mathrm{C}$. The specific rate constant calculated using second order reaction was found decrease with increase of methanol and ethanol content, tabulated in Table-I the evaluated thermodynamic activation parameter has been enlisted in Table-II.

\section{RESUlT AND DisCUSSION}

A. Solvent Effect on Specific Rate

In order to highlight the effect of the solvent on specific rate constant values of the reaction, the specific rate constant were calculated with help of second order reaction and calculated values is inserted in Table-I . From Tab-1 it is observed that the values of specific rate constant is decrease with increase of temperature which is quite in agreement with theory of Hughes and Ingold[4] and Singh A K[5]

TABLE I. HYDROLYSIS OF ETHYL-CINNAMATE SPECIFIC RATE CONSTANT [K X10 $\left.{ }^{3}(\mathrm{DM})^{3} / \mathrm{MOLE} / \mathrm{MINT}\right]$ VALUES OF ALKALI CATALYZED IN WATER-METHANOL MEDIA

\begin{tabular}{|r|r|r|r|r|}
\hline $30 \%$ & $40 \%$ & $50 \%$ & $60 \%$ & $70 \%$ \\
\hline 15.66 & 11.22 & 10.00 & 8.12 & 6.45 \\
\hline 20.89 & 16.59 & 13.48 & 10.59 & 8.49 \\
\hline 27.54 & 21.87 & 16.98 & 13.64 & 10.83 \\
\hline 38.01 & 30.19 & 23.17 & 18.62 & 14.62 \\
\hline 45.70 & 36.30 & 27.86 & 22.38 & 17.74 \\
\hline
\end{tabular}

B. Solvent effect on Thermodynamic Activation Parameters of Reaction

For better study of solvent effect on thermodynamic activation parameters, such as Enthalpy of activation $\left(\Delta H^{*}\right)$, Free energy of activation $\left(\Delta \mathrm{G}^{*}\right)$, and Entropy of activation $\left(\Delta S^{*}\right)$ were taken into account as they have great significance. These parameters are calculated using Wynne-jones[6] and Eyring equation have been recorded in Table-II

In order to highlight the effect of solvent on these activation parameters, the value of these parameters were 
plotted against mole\% of methanol which is shown in figure 1 , $2 \& 3$.

From fig- 2 and the value $s$ of $\Delta \mathrm{G}^{*}$ recorded in Tab-II, obviously indicate that the variation in

$\Delta \mathrm{G}^{*}$ is small and it increases from 94.98 to $97.19 \mathrm{kj} / \mathrm{mole}$ at $30^{\circ}$ cwith change of proportion of methanol from $30 \%$ to $70 \%(\mathrm{v} / \mathrm{v})$ The small but considerable increase in $\Delta \mathrm{G}^{*}$ and non linear variation in $\Delta \mathrm{H}^{*} \& \Delta \mathrm{S}^{*}$ curves with the increasing mole $\%$ as shown in figure-1 and fig-3 are indication of specific salvation taking place in process of activation as already proposed by Saville \&Hudson[7.] ,Tomilla et al.[8],
Esemongy[9] and Cleve[10] have also observe the similar increase in $\Delta \mathrm{G}^{*}$ values. Increase in $\Delta \mathrm{G}^{*}$ with simultaneous decrease in

$\Delta \mathrm{H}^{*} \& \Delta \mathrm{S}^{*}$ values is only possible when extent (degree) of depletion in $\Delta \mathrm{S}^{*}$ value is greater than $\Delta \mathrm{H}^{*}$ values and from this, it may be inferred that alkali catalysed hydrolysis of ethyl cinnamate in water-methanol media act as Entropy inhibitor and Enthalpy stimulator solvent. Such inference have also recently been supported by recent view of Singh A K [11]

TABLE II. Thermodynamics Activation Parameters of the ReAction IN WATER- ACETONE Media $\Delta \mathrm{H}^{*}$ AND $\Delta \mathrm{G}^{*}$ IN KJ/MOLE, $\Delta \mathrm{S}^{*}$ IN J/K/MOLE

\begin{tabular}{|c|c|c|c|c|c|c|c|c|c|c|c|c|}
\hline \multirow{2}{*}{$\begin{array}{l}\text { \% of } \\
\text { MEOH }\end{array}$} & \multirow{2}{*}{$\begin{array}{l}\text { Mole } \\
\%\end{array}$} & \multirow{2}{*}{$\begin{array}{l}\Delta \mathbf{H}^{*} \text { in } \\
\mathbf{K} / \mathbf{M o l e}\end{array}$} & \multicolumn{2}{|c|}{$20^{\circ} \mathrm{C}$} & \multicolumn{2}{|c|}{$25^{0} \mathrm{C}$} & \multicolumn{2}{|c|}{$30^{\circ} \mathrm{C}$} & \multicolumn{2}{|c|}{$35^{0} \mathrm{C}$} & \multicolumn{2}{|c|}{$40^{\circ} \mathrm{C}$} \\
\hline & & & $\Delta \mathbf{G}^{*}$ & $-\Delta \mathbf{S}^{*}$ & $\Delta \mathbf{G}^{*}$ & $-\Delta \mathbf{S}^{*}$ & $\Delta \mathbf{G}^{*}$ & $-\Delta \mathbf{S}^{*}$ & $\Delta \mathbf{G}^{*}$ & $-\Delta \mathbf{S}^{*}$ & $\Delta \mathbf{G}^{*}$ & $-\Delta \mathbf{S}^{*}$ \\
\hline $30 \%$ & 16.03 & 53.31 & 93.64 & 137.64 & 94.27 & 137.44 & 94.98 & 137.52 & 95.60 & 137.30 & 96.31 & 137.38 \\
\hline $40 \%$ & 22.90 & 52.95 & 94.20 & 140.78 & 94.91 & 138.42 & 95.65 & 140.89 & 96.31 & 140.77 & 97.03 & 140.83 \\
\hline $50 \%$ & 30.82 & 52.87 & 94.68 & 142.6 & 95.44 & 140.30 & 96.23 & 143.10 & 96.96 & 143.14 & 97.75 & 143.38 \\
\hline $60 \%$ & 40.06 & 51.28 & 95.16 & 149.76 & 95.88 & 147.24 & 96.72 & 149.96 & 97.43 & 149.83 & 98.23 & 150.00 \\
\hline $70 \%$ & 50.97 & 50.51 & 95.64 & 154.02 & 96.39 & 151.44 & 97.19 & 154.05 & 97.96 & 152.56 & 98.77 & 154.18 \\
\hline
\end{tabular}

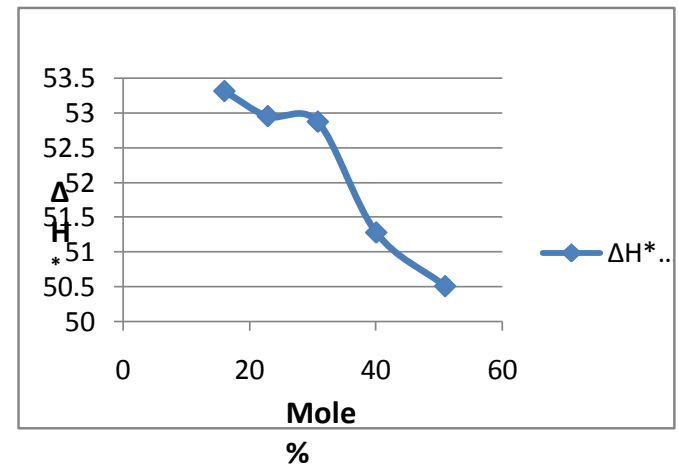

Figure 1. Variation of $\Delta \mathrm{H}^{*}$ with mole $\%$ at $20^{\circ} \mathrm{c}$ (water-methanol)

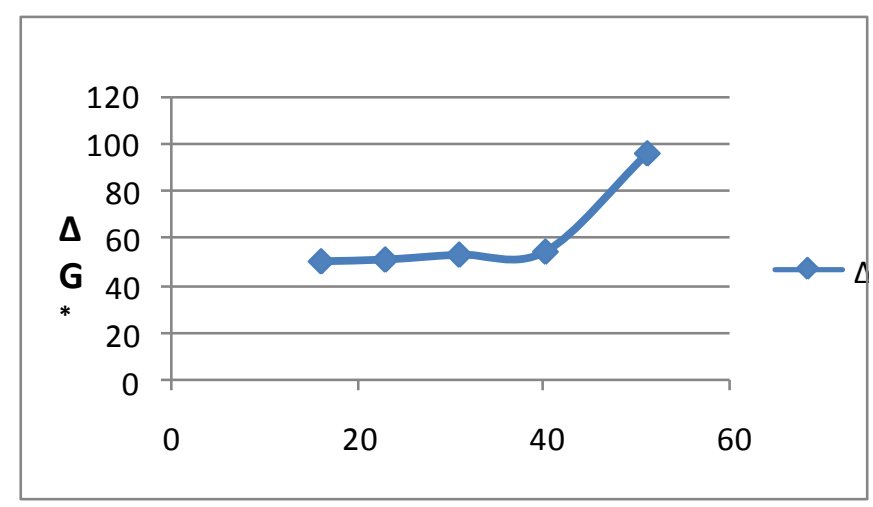

Figure 2. Variation of $\Delta \mathrm{H}^{*}$ with mole $\%$ at $20^{\circ} \mathrm{c}$ (water-methanol)

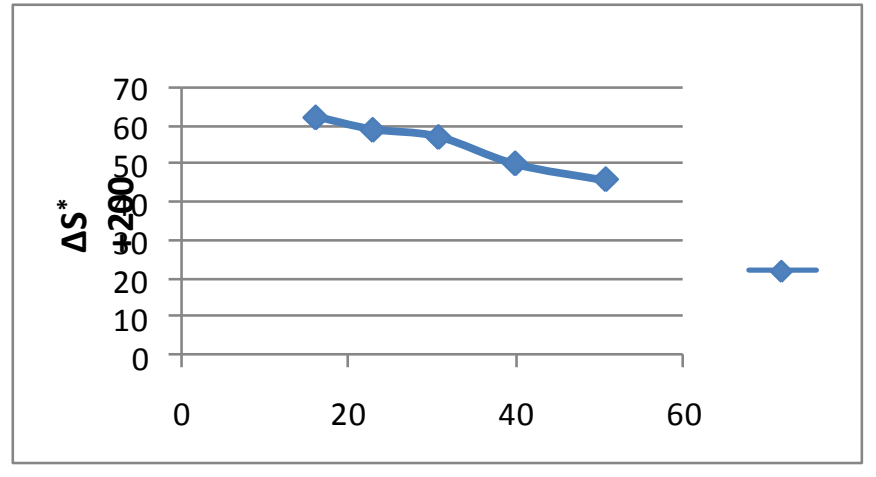

Figure 3. Variation of $\Delta \mathrm{S}^{*}+200$ with mole $\%$ at $20^{\circ} \mathrm{c}$ (water-methanol)

\section{Evaluation of Iso-kinetic Temperature and Solvent-Solute Interaction}

In the light of Barclay [12] and Butler relationship between Enthalpy and Entropy of Activation, which is as follows?

$$
\delta \mathbf{m}\left(\Delta \mathbf{H}^{*}\right)=\beta \delta \mathbf{m}\left(\Delta \mathbf{S}^{*}\right)
$$

It is straight line equation representing the relationship between Enthalpy and Entropy of Activation. $\beta$ is the Isokinetic temperature.

From the data available in the table II, the plot of $\Delta \mathrm{H}^{*}$ and $\Delta \mathrm{S}^{*}$ in both the solvent system in Fig. 4 and from the slope of straight line, the value of Iso-kinetic temperature was calculated to be 200 (water-Methanol) media.

From the value of Iso-kinetic temperature which is much less than 300, it is concluded that there is slow change in the structure of the reactant or in the solvent or in both due to weak interaction between solvent and solute present in both the reaction media in similar way as reported by Lefler [13] 
Our this conclusion has been recently supported by Singh A K.[14]

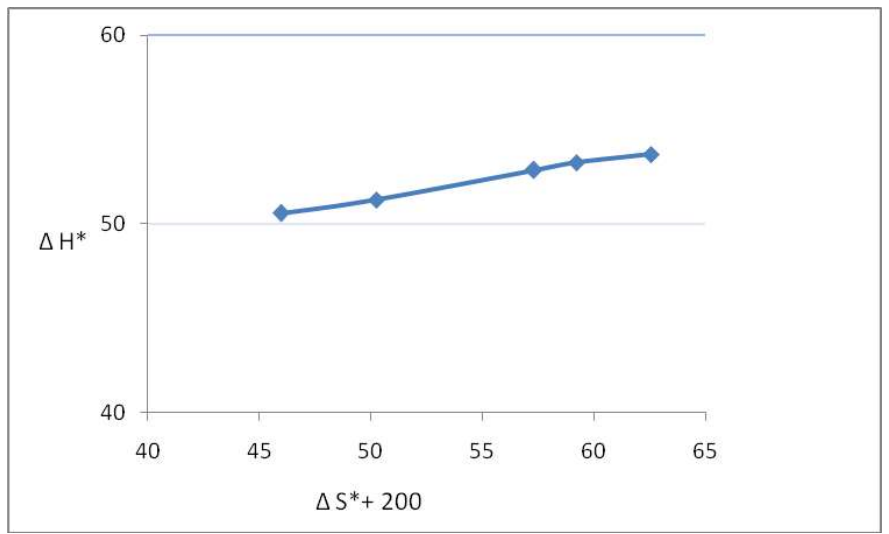

Figure 4. Variation of $\Delta \mathrm{H}^{*}$ with $\Delta \mathrm{S}^{*}$ at $25^{\circ} \mathrm{C}$ (water-methanol) system

\section{CONCLUSION}

The result of this work indicate that the rate of hydrolysis of Ethyl cinnamate, decreasing trend at all temp with increasing mole\% of co-solvent which appear that transition state is more desolveted than initial state. The enhancement in the value of and $\Delta \mathrm{G}^{*}$ with simultaneous decrease in $\Delta \mathrm{H}^{*} \& \Delta \mathrm{S}^{*}$ for the hydrolysis ethyl cinnamate in water- Methanol is enthalpy dominating and Enthalpy control. The Values of Iso-kinetic which is less than 300, clearly indicates that there is no appreciable interaction between solvent and solute present in the reaction media, i.e. reaction is not ion-dipole but ionmolecule type.

\section{ACKNOWLEDGMENT}

My special gratitude to my supervisor Prof. R. T. Singh for his proper guidance and thanks to my friend Dr Ajit, Dr. Parag and Mr. L. K. Tiwari for his cooperation during preparation of this content.

\section{REFERENCES}

[1] Nada A. Al Jallal. Amer M. Ismail: Solvent effect o kinetics of amide bond cleavage in p. chloro and p. bromo oxazolinanes in Acetone nitrilewater mixture. J. Solution chem., 41, 2154-63, 2012.

[2] Magda F. Fathalla, Kinetics of reaction of 2-chloro-quinosalin with hydroxide ion in $\mathrm{CAN}-\mathrm{H}_{2} \mathrm{O}$ and DMSO- $\mathrm{H}_{2} \mathrm{O}$ binary solvent mixture $\mathrm{j}$. Solution Chem., 40, 1258-70, 2011

[3] Singh A K., "Solvent Effect on the Enthalpy and Entropy of Activation for the Hydrolysis of Ethyl Cinnamate in Mixed Solvent System",
International Journal of Engineering and Applied Computer Science (IJEACS) Volume: 02, Issue: 02, February 2017

[4] Hughes E.D. and Ingold C.K, " Mechanism of substitution at saturated carbon atom part IV, A discussion of constitution and solvent effect on mechanism, kinetics, velocity, and orientation of substitution". $j$ chem. Soc 1935, 244- 255

[5] Singh A K., The Influence of Solvent on the Solvolysis of EthylCinnamate in Water Acetone Mixed Solvent System." International Journal of Engineering and Applied Computer Science (IJEACS) Volume: 02, Issue: 02, February 2017

[6] Wynne-Jones W. F. K, and Eyring, H,: “ The Absolute Rate of Reaction in condense Phase". J. chem. phys. 3, 492-502, 1935.

[7] Saville B.J. and Hudson, R.E.: J. chem. soc. 4114, 1955

[8] Tommila. E., "Influnce of solvent on reaction velocity." Acta. Chem. Scand 9 (1955) pp957-988

[9] Elsemogy, M.M., Abu Elamayem, M.S., and Mussa, M.N.H.,: Z. Physik chem (Neuetold) 94, 69, 1975

[10] Cleave, N J ., Soumen Kemi., 45B 2851935

[11] Singh A K "Solvent Effect on the Enthalpy and Entropy of Activation for the Hydrolysis of Ethyl Cinnamate in Mixed Solvent System." Volume: 02, Issue: 04, April 2017. PP 123-126.

[12] Barclay L. and Butler, J.A.V. "The Entropy of solution.”J. Am. chem. soc. $34,1445,1938$

[13] Lefler J.E. "Entropy relationship and implication for organic chemistry."J. org. chem., 20, 1201, 1955

[14] Singh A K., "Solvolysis Rate and Activation Parameter of Ethyl Acetate in mixed Dipolar Organic Solvent Systems- A Solvent Effect." International Journal for Research in Applied Science \& Engineering Technology $X$, October 20(IJRASET) Volume 4 Issue 16 PP704-710

\section{AUTHOR PROFILE}

Dr. A. K. Singh is working as Asst. Professor of Chemistry in College of Engineering of Teethankar Mahaveer University, Moradabad, India since 2010. He holds Master of Science in Physical Chemistry, awarded in 1989, from Magadh University, Gaya followed by Doctor of Philosophy (Ph.D.) in Kinetic Solvent Effect, awarded in 2009 from VKS University Ara, India. He has studied different salvation capacity of different reaction media (e.g. Water-DMSO, Water-

DMF,Water-Aceton. Water-Methanol etc) on the Specific Rate Constant value of the Reaction, the Iso- Composition, Iso- Dielectric Activation Energy, the Number of Water and Solvent Molecules Associated the Activated complex of the Reaction in order to decide the Nature of Mechanistic path of the Reaction, Thermodynamic Activation Parameter of the Reaction, the value of Iso Kinetic Temp on the Reaction in order to Explore the Idea of SolventSolute Interaction in More Media. He has published seventeen research articles in his credits.

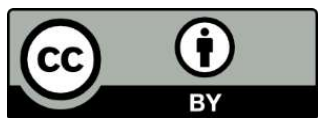

(C) 2017 by the author(s); licensee Empirical Research Press Ltd. United Kingdom. This is an open access article distributed under the terms and conditions of the Creative Commons by Attribution (CC-BY) license. (http://creativecommons.org/licenses/by/4.0/). 